\title{
Test yourself: question - a 62-year-old lady with painful swelling of right hand index finger for the last 8 weeks
}

\section{Sajid Butt ${ }^{1} \cdot$ Roberto Tirabosco ${ }^{2} \cdot$ Asif Saifuddin $^{1}$}

Published online: 20 July 2020

(C) ISS 2020
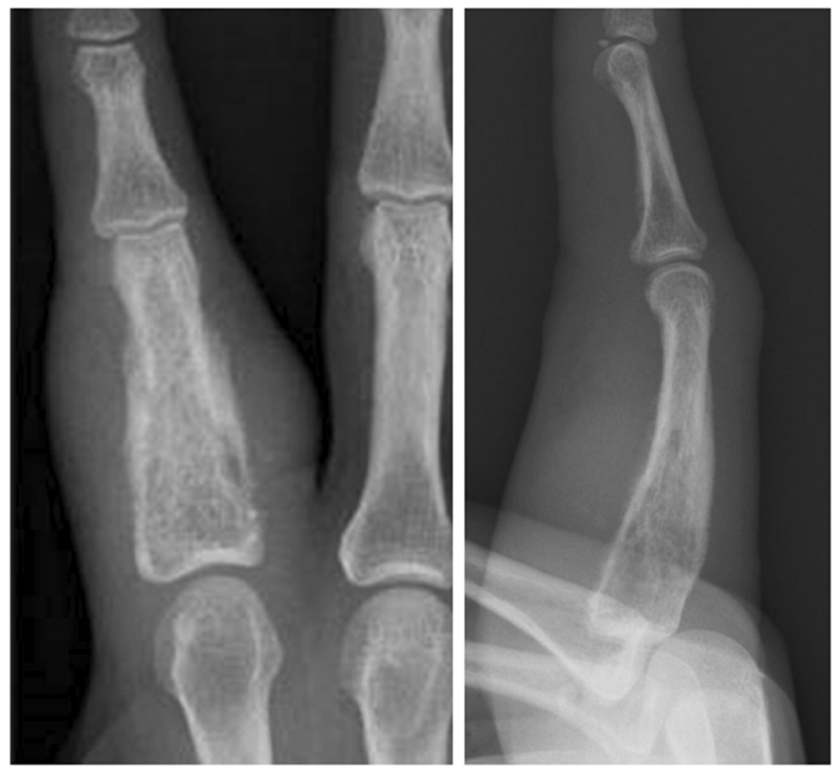

Fig. $1 \mathrm{AP}$ and lateral radiographs of the right index finger

The diagnosis can be found at doi: https://doi.org/10.1007/s00256-02003553-2

Sajid Butt

Sajid.Butt@nhs.net

1 Department of Radiology, Royal National Orthopaedic Hospital, Stanmore, UK

2 Department of Histopathology, Royal National Orthopaedic Hospital, Stanmore, UK 

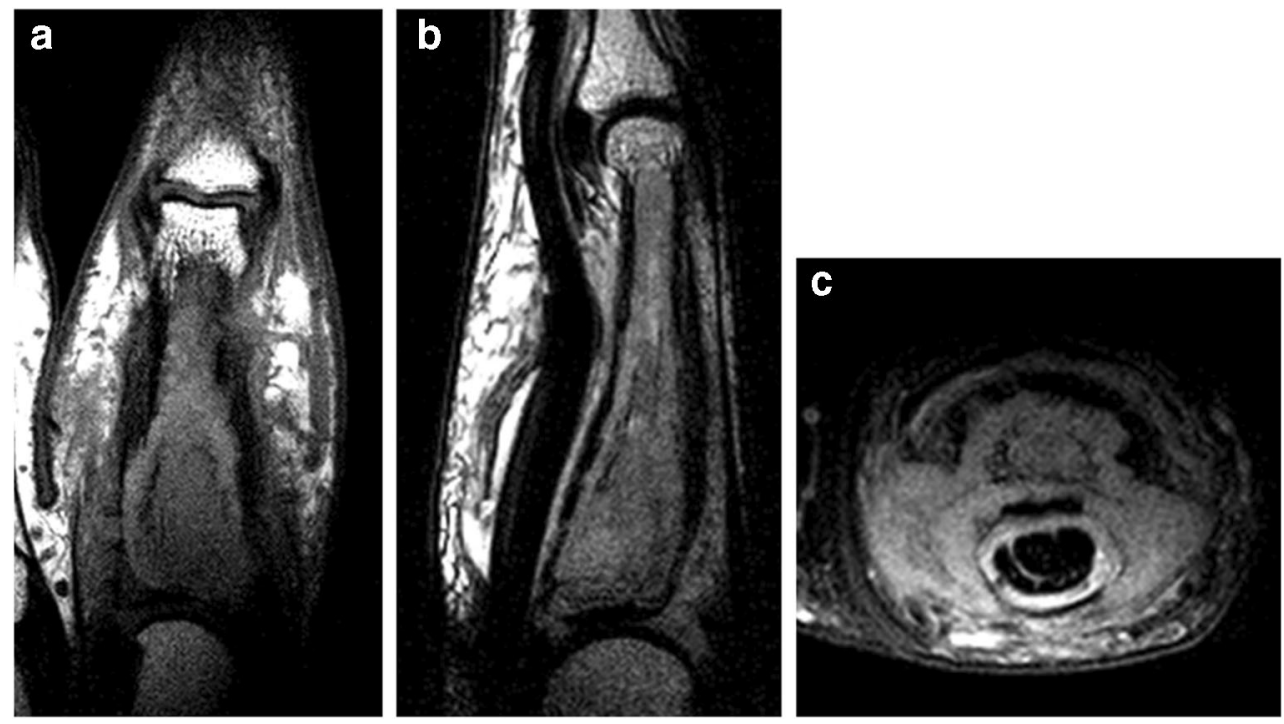

Fig. 2 (a) Coronal T1W TSE, (b) sagittal STIR, and (c) axial SPAIR MR images

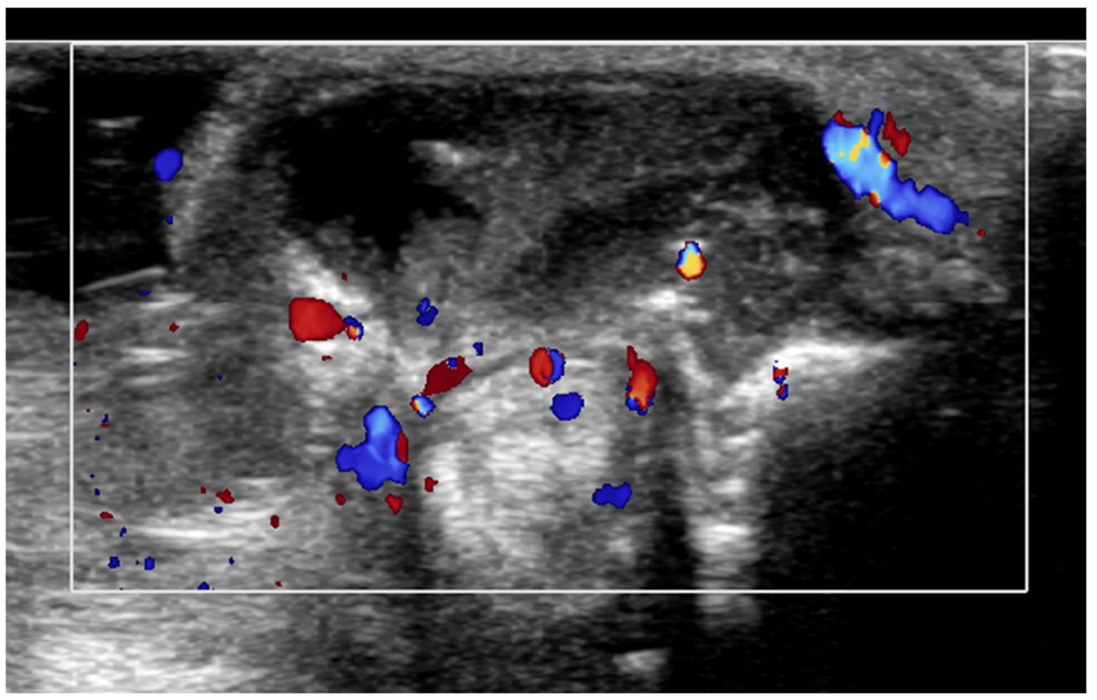

Fig. 3 Axial Doppler US image 


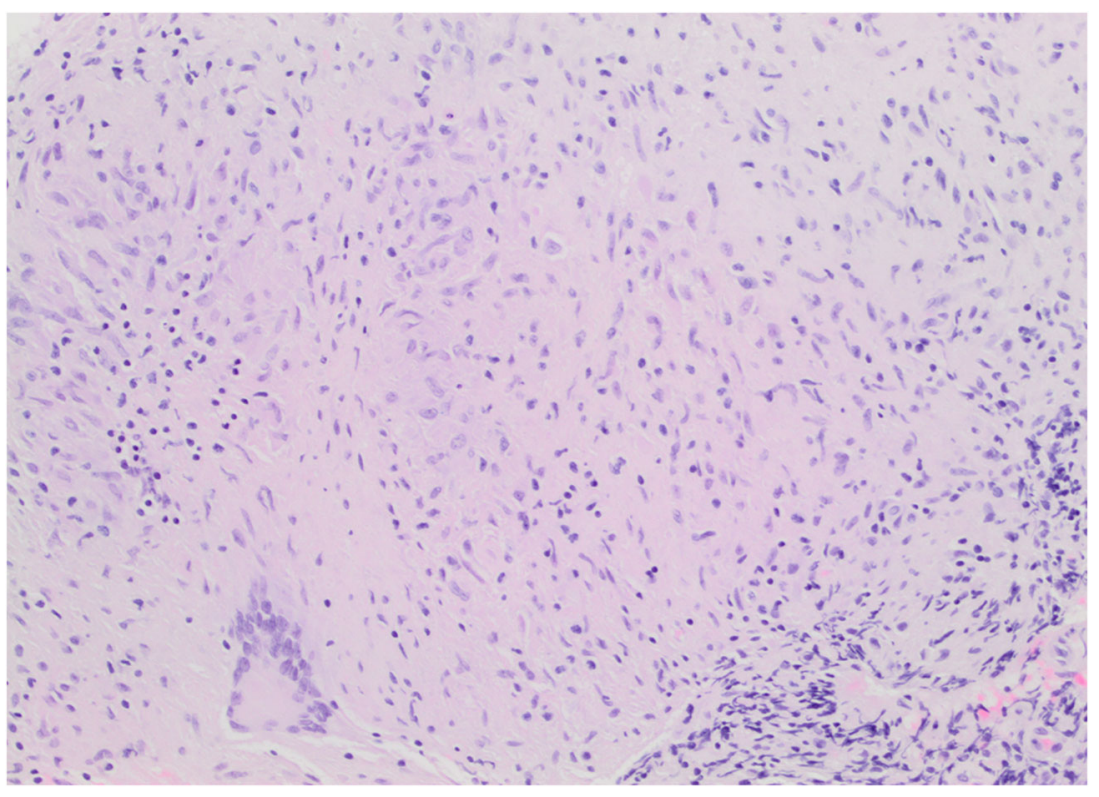

Fig. 4 Photomicrograph of $\mathrm{H}$ and $\mathrm{E}$ stain of biopsy specimen. $(\times 10)$

Publisher's note Springer Nature remains neutral with regard to jurisdictional claims in published maps and institutional affiliations. 